\title{
Closure of Post-pneumonectomy Bronchial Stump Dehiscence using Amplatzer Device
}

\author{
Asma Navasakulpong ${ }^{1}$, Supaporn Roymanee ${ }^{2}$ \\ ${ }^{1}$ Division of Respiratory and Respiratory Critical Care Medicine, Faculty of Medicine; ${ }^{2}$ Pediatric Cardiology unit, Department of \\ Pediatrics; Prince of Songkla University, Hatyai, Songkhla, 90110, Thailand.
}

\section{Corresponding Author:}

Dr. Asma Navasakulpong

Email: navasakulpong@hotmail.com

This is an Open Access article distributed under the terms of the Creative Commons Attribution License (creativecommons.org/ licenses/by/3.0).

Received Accepted

Published

\section{Introduction}

Post-pneumonectomy bronchopleural fistula (BPF), also known as main stump dehiscence is a challenging situation and difficult management problem. It is also associated with high morbidity and mortality. The treatment of BPF is varied and dependent on the size of the BPF, time course in relation to surgery and surgeon's experience. Surgical therapies have included primary or delayed closure with creation of an Eloesser cavity with or without omental or muscle flap reinforcement. Newer less invasive techniques utilize bronchoscopy to deliver bio-adhesives, coils, or stents for BPF closure [1-5]. Use of the
Amplatzer device, which is commonly used for transcather treatment in congenital heart disease, is one such technique that has been described [3,610]. The author's presents the first case of our hospital with Amplatzer device closure in a large stump dehiscence after a right pneumonectomy from massive bleeding due to metastasis renal cell carcinoma.

\section{Case Report}

A 61-year-old male was diagnosed metastasis renal cell carcinoma at right lung with massive hemoptysis. The patient was performed right lung pneumonectomy and then had complication of right main bronchial stump dehiscence. Due to the 
stump dehiscence, patients experienced several bouts of pneumonia at left lung.

The need to clear secretions usually kept the patient awake late at night. He was intermittently given oral antibiotic when he had more purulent sputum but the treatment did not help much. The computed tomography of the chest confirmed the leakage of the stump dehiscence. The patient had been treated with second line chemotherapy (Nivolumab) for his renal cell carcinoma and often needed to be treated for his infections. Because of the patient's borderline performance status, the surgeon declined to attempt to perform surgical repair on the bronchial stump dehiscence. The patient was transferred to the chest unit for consideration of bronchoscopic closure stump dehiscence. He was hypostenic built and good consciousness. His vital signs were stable. The patient underwent the procedure under intubation and used general anesthesia (GA). Bronchoscopy revealed a multiple opening of the right bronchial stump [Fig.1]. After locating the stump dehiscence under visualized flexible bronchoscopy (BF-1T180 Video Bronchoscope; Olympus Corporation, Tokyo, Japan), the first self-expanding nitinol made AVP II occlude No. 16 [Fig.2] (St. Jude Medical, St. Paul, Minnesota, USA) was delivered under bronchoscopic guidance over a delivery cable into the middle hole of fistulas and followed by fluoroscopy to assure proper device positioning and sealing of the fistulas. The second AVP II occluder No.8 was placed into the residual fistula later, using the same technique. Checking the complete occlusion of the fistulas under direct bronchoscopic view and fluoroscopy with dynamic bronchography was done at the end of procedure to confirm the position of devices and the complete occlusion [Fig.3]. The patient tolerated the procedure without any complications, was extubated and discharged home the following day The chest $\mathrm{x}$-ray showed the decrease of pneumothorax in two months [Fig.4]. No pulmonary infection occurred after the procedure for twenty months. However, at that time

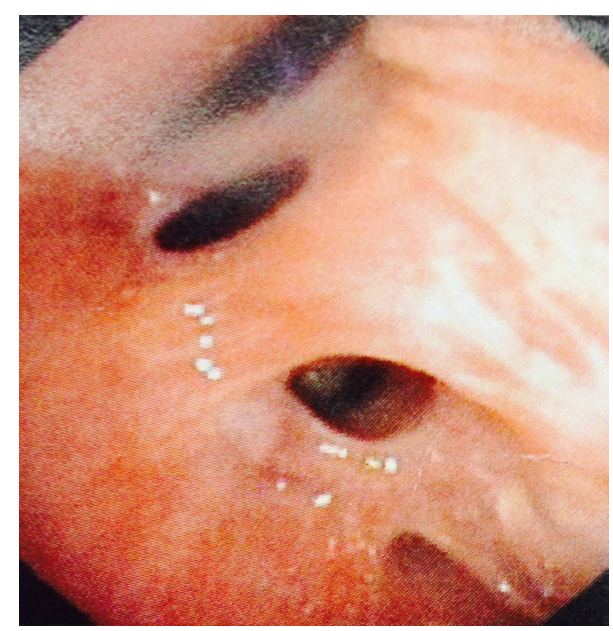

Fig.1: Right main bronchial stump dehiscence.

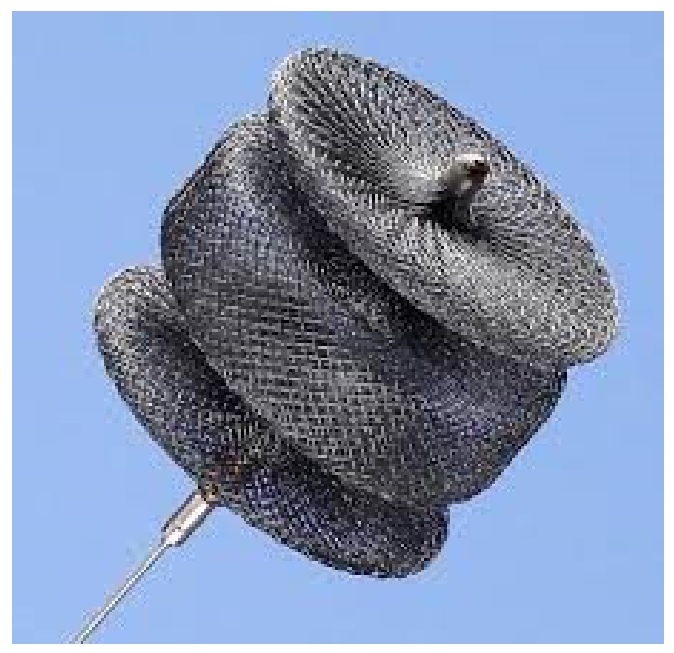

Fig.2: Amplazter vascular plug II, size 3-22 mm.
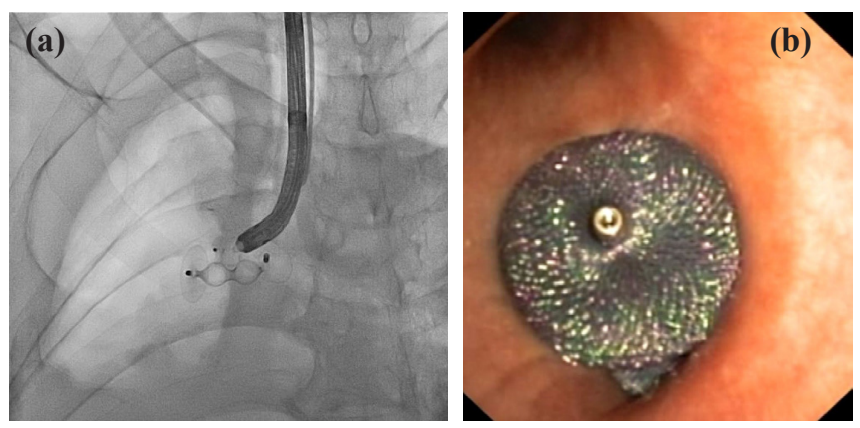

Fig.3(a): Fluoroscopic view of two Amplazter vascular plugs II, (b): Bronchoscopic view at the end of procedure, Amplazter vascular plugs II completely occluded right main stump dehiscence. 
the patient was diagnosed with brain metastasis and expired after two years of treatment.

\section{Discussion}

This is the first report published in Thailand demonstrating the use of a novel technique for endobronchial closure of stump dehiscence by the implantation of Amplatzer devices. Amplatzer devices have traditionally been employed by interventional cardiologists to close atrial septal defects or abnormal vessels. The Amplatzer vascular plug II is a self-expanding cylindrical occluding device, made from nitinol wire mesh that allow the device to compress inside a catheter and, when released from the delivering catheter, returns to its shape to occlude the target vessel or in our case the airway lumen. The device has platinum markers on both ends. A stainless-steel micro-screw is welded to one of the platinum marker bands, which allows attachment to the $135-\mathrm{cm}$-long delivery cable. It is available in diameters ranging from 3-22 $\mathrm{mm}$ so that the occluder can be matched to the size of the defect. Moreover, it is deliverable through 4-7 Fr sheath which allow it to pass easily via the bronchoscopy that made it more advantageous than other occluders. The technique described appears to be very useful in patients with stump dehiscence who fail conservative therapy or who are unsuitable candidates for traditional surgeries. Other devices are available for attempted main stump dehiscence closure such as endobronchial valves and stents. However, such devices are either not available in Thailand commercially or have complicated and/or expensive delivery systems. In contrast to previous procedures $[6,7,9,10]$ we applied the occluder device in the intubated patient using a large endotracheal tube (No.8) under GA instead of moderate sedation and optimized positive pressure ventilation during procedure. The procedure was well tolerated by the patient who displayed no postoperative complications. The patient satisfied with this intervention and he did not have pneumonia for 20 months after treatment. The long-term result of this application was unknown due to patient passed away two years later from brain metastasis.
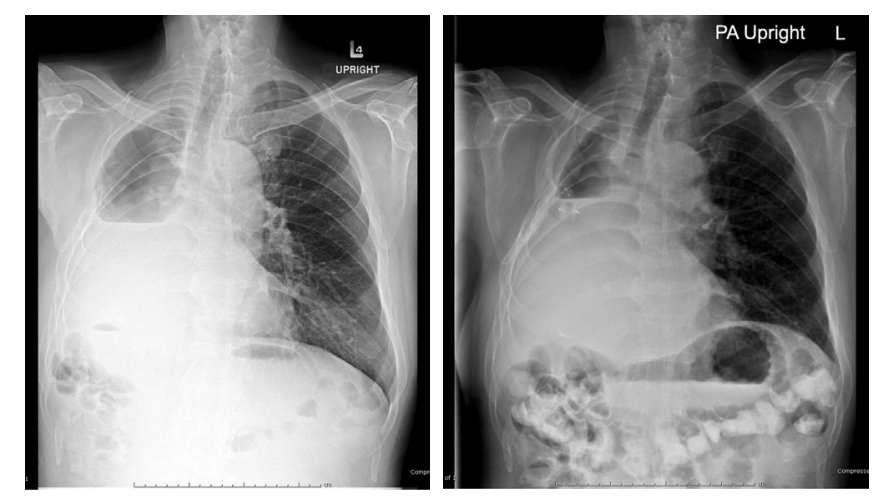

Fig.4(a): Chest X-ray before procedure, (b): Chest X-ray two months after procedure revealed the decrease of pneumothorax.

\section{Conclusion}

This case report highlights the utility of the Amplatzer vascular plug II to facilitate the closure of BPFs in marginal patients who fail conservative therapy. It is safe, less invasive and easily placed by using flexible bronchoscopy under GA or moderate conscious sedation.

Acknowledgements: I would like to express my deep gratitude to Professor Hermann Tonn, my mentor, for this guidance, enthusiastic encouragement and useful technique for this procedure. I would also like to thank Dr. Roymanee for her advice and assistance for this successful procedure.

Contributors: AN: manuscript writing, patient management; SR: manuscript editing, patient management; AN will act as guarantor. Both authors approved the final version of this manuscript.

Funding: None; Competing interests: None stated.

\section{References}

1. Chae EY, Shin JH, Song HY, Kim JH, Shim TS, Kim DK. Bronchopleural fistula treated with a silicone-covered bronchial occlusion stent. The Annals of Thoracic Surgery. 2010;89:293-296.

2. Ferguson JS, Sprenger K, Van Natta T. Closure of a bronchopleural fistula using bronchoscopic placement of an endobronchial valve designed for the treatment of emphysema. Chest. 2006;129:479-481.

3. Lois M, Noppen M. Bronchopleural fistulas: an overview of the problem with special focus on endoscopic management. Chest. 2005;128:3955-3965.

4. McManigle JE, Fletcher GL, Tenholder MF. Bronchoscopy in the management of bronchopleural fistula. Chest. 1990;97:1235-1238. 
5. Tao H, Araki M, Sato T, Morino S, Kawanami R, Yoshitani $\mathrm{M}$, et al. Bronchoscopic treatment of postpneumonectomy bronchopleural fistula with a collagen screw plug. The Journal of Thoracic and Cardiovascular Surgery. 2006;132:99-104.

6. Fruchter O, Bruckheimer E, Raviv Y, Rosengarten D, Saute M, Kramer MR. Endobronchial closure of bronchopleural fistulas with Amplatzer vascular plug. European Journal of Cardio-thoracic Surgery. 2012;41:46-49.

7. Fruchter O, El Raouf BA, Abdel-Rahman N, Saute M, Bruckheimer E, Kramer MR. Efficacy of bronchoscopic closure of a bronchopleural fistula with amplatzer devices: long-term follow-up. Respiration. 2014;87:227233.
8. Fruchter O, Kramer MR, Dagan T, Raviv Y, AbdelRahman N, Saute M, et al. Endobronchial closure of bronchopleural fistulae using amplatzer devices: our experience and literature review. Chest. 2011;139:682687.

9. Gulkarov I, Paul S, Altorki NK, Lee PC. Use of Amplatzer device for endobronchial closure of bronchopleural fistulas. Interactive Cardiovascular and Thoracic Surgery. 2009;9:901-902.

10. Kramer MR, Peled N, Shitrit D, Atar E, Saute M, Shlomi $\mathrm{D}$, et al. Use of Amplatzer device for endobronchial closure of bronchopleural fistulas. Chest. 2008;133:14811484. 